\title{
Accidents, Taxes, Liability Rules and Insurance
}

\author{
H.S.E. Gravelle*
}

\section{Introduction}

Individuals frequently indulge in activities, such as driving, which carry the risk of an accident with another individual involved in the same activity. Such accidents are bilateral: the probability of the accident occuring depends on the amounts of care exercised by both parties. If an accident does occur, both parties will bear losses which depends on the liability rules in force.

Risk averse individuals will wish to insure. Insurers cannot easily observe the amount of care takem by an insured. This asymmetrical information will give rise to moral hazard: a dilution of incentives to take care. Rational insurers and insureds will seek to mitigate the effects of moral hazard by the terms of their insurance contracts. Typically, the privately efficient insurance contract will involve less than full compensation for the accident (See Shavell [1979a, 1979b]).

There are two potential efficiency justifications for government intervention in this situation. First, each inividual will choose a level of care which reflects the accident losses which he or she will suffer and will ignore that part of the total accident cost which falls on the other party to the accident. Additional care by one individual increases the expected utility of the other, but the beneficial reciprocal technological externality is neglected when each individual chooses a care level. Second, there is a pecuniary externality arising from the insurance contract: with moral hazard, the insured's choice of care does not take full account of its impact on the insurer's expected costs. Government policies which increase the care of the insured will reduce the insurance premium paid for any given cover and this may more than offset the increased cost of care to the insured.

The government has a wide range of policy instruments which it may be able to use to achieve efficiency gains. The state may be able to monitor and control the level of care in ways which are not available to private individuals. It could, for example, set standards of care and enforce them by a policing system at considerably lower cost than would be achieved by private insurers. Second, the costs falling on insureds as a result of the accident can be

* Queen Mary College, University of London. The comments of participants in the University College (Cardiff) economics seminar and in the Geneva Association - European Association for Law and Economics conference on insurance and liability in Geneva, April 1986 are gratefully acknowledged. The paper has also benefitted from the suggestions of three referees. 
altered. The state can levy taxes on, or pay compensation to, individuals who have an accident. Different legal liability systems can be imposed (for example: strict liability, no fault, negligence, comparative negligence). Third, it may be possible to alter the price of care (or of complements or substitutes for care) via commodity taxes or subsidies. For example, an increase in the price of petrol might lead to lower traffic speed. Fourth, private insurance contracts can be regulated. Private insurance could be banned entirely, or the amount of cover restricted, or third party cover may be made compulsory.

This paper considers how the government could choose a mix of policies to promote efficiency in accident prevention and risk sharing. It will be assumed that it is not possible for the government (via the legal system or otherwise) to monitor or observe individual levels of care. The policies examined in this paper are the last three listed in the previous paragraph: allocation of accident costs, via accident taxes and liability rules (but excluding negligence systems), taxation of care and regulation of private insurance. Since it is generally true that these policies are not sufficient to achieve a first best, or fully efficient, resource allocation, this paper complements the analyses of imperfect policing and regulation of care in Hansson and Skogh [1987], Skogh [1982] and Shavell [1984].

Before presenting the details of the model in section 2 and the derivation and discussion of its results in section 3, it may be useful to relate the approach takem in the paper to some of the main contribution in the literature. Some authors (Brown [1973], Diamond [1974], Diamond and Mirrlees [1975], Shavell [1980]) examine the efficiency of alternative legal liability rules, but assume that individuals are risk neutral, so that there is no consideration of the effects of insurance on incentives for care. It has been shown that negligence or strict liability with contributory negligence defences, both lead to an efficient choice of care, but that no legal liability rule can ensure an efficiency activity level.

More general cost shifting schemes, which do not assume that payments by one party to an accident must accrue to the other party, have been considered by Vickrey [1968], Green [1976], Knoeber [1978], Tullock [1981] and Hindley and Bishop [1983]. If the total costs of the accident are imposed on both parties by a set of accident taxes, then both are induced to take an efficient level of care. This result also rests on the assumption that individuals are risk neutral and do not insure.

The implications of risk aversion and insurance for the choice of liability regime were examined by Shavell [1982], in the context of unilateral accidents, where only one party can exercise care. The choice between liability rules is complicated by their impact on risk bearing, but there are no grounds for government regulation of insurance contracts, even in the presence of moral hazard. Landes [1982] considers bilateral accidents and the implications of a no-fault rule liability rule, but it is assumed initially that insurers can observe care so that there is no moral hazard and, when this assumption is relaxed, there is no analysis of the choice of a privately efficient insurance contract. Boyer and Dionne [1985] consider moral hazard and shown that, if the government has better information than insurers and can observe care, a negligence rule, with an appropriately chosen due care standard, will lead to efficiency. If there is no private insurance, but a single public insurer, it is possible for to offer a long term insurance contract which will induce each individual to choose the efficient care level, even if the government cannot observe care. This result does not hold if individuals have finite lives. Finite long term contracts can mitigate moral hazard, but they will not eliminate it. 
Finally, two recent papers have examined how commodity taxes and subsidies can improve efficiency in the presence of moral hazard. Arnott and Stiglitz [1986] assume that there is only government insurance, whilst in Gravelle [1986] there are private insurance contracts. Both papers are concerned only with unilateral accidents, which do not impose any third party losses, so that liability rules are not examined.

\section{Analytical framework}

In this section we set out the model to be used to analyse the situation sketched in the introduction: bilateral accidents, two risk averse individuals, private insurance, moral hazard and the government able to shift accident costs, tax or subsidise care and regulate private insurance contracts.

The probability of an accident between two individual is $\pi\left(x_{1}, x_{2}\right)$, a decreasing strictly convex function of the care levels $\left(x_{1}, x_{2}\right)$ chosen by both individuals. Care has a constant cost per unit (price) of $p$.

An accident imposes an initial cost of $L_{i}$ on individual $i$. The government can alter the initial distribution of costs by its choice of liability rule and by taxing or compensating the individuals if the accident occurs. Both methods of cost shifting are captured by defining an accident $\operatorname{tax} T_{i}$ which is paid by $\mathrm{i}$ if an accident occurs. For example:

(a) $\left(T_{1}, T_{2}\right)=\left(L_{1},-L_{2}\right)$ is a regime in with individual 1 is strictly liable for all the accident costs and has to fully compensate individual 2 ;

(b) $\left(T_{1}, T_{2}\right)=(0,0)$ is a no-fault system in which each bears his own accident costs;

(c) $\left(T_{1}, T_{2}\right)=\left(-L_{1},-L_{2}\right)$ is full compensation by the government for accident costs;

(d) $\left(T_{1}, T_{2}\right)=\left(L_{2}, L_{1}\right)$ ensures that individuals bear both their own accident costs and those of the other party. This is the scheme suggested by Vickrey [1968] and others as having desirable effects on the choice of care.

Negligence regimes would correspond to accident taxes which were contingent on the level of care. We assume that only the individual can observe his level of care, so that direct control of care or taxes contingent on care are not feasible.

The government may be able to alter the price of care by taxation, even if cannot observe care by any individual. It could, for example, tax petrol (encourage lower speeds) or subsidise tyres and servicing. Letting $t$ be the tax on care, and choosing units so that the constant, net of tax, price of care is unity, the price of care is $p=(1+t)$. We assume that the government has no motive for raising revenue from individuals engaged in the risky activity and that it can make a payment of $z_{j}$ to each individual engaged in the activity, with $z_{\text {z not }}$ neing contingent on the occurrance of the accident. The government's taxes and subsidies are constrained to satisfy its budget constraint, expressed in expected value term as

$$
\pi \Sigma T_{i}+t \Sigma x_{i}-\Sigma z_{i} \geq 0
$$

Each individual can buy insurance (unless prevented by government policy) from competitive, risk-neutral, private insurers, choosing a level of cover $\alpha_{i}$ in exchange for a fair 
premium $\gamma_{i}=\pi \alpha_{i}$. Insurers cannot observe care by the individual. After taxes and insurance, the individual has income

$$
\begin{aligned}
& y_{i o}=y_{i}-p x_{i}-\gamma_{i}+z_{i} \\
& y_{i t}=y_{i}-L_{i}-p x_{i}-\gamma_{i}+z_{i}+\alpha_{i}-T_{i}
\end{aligned}
$$

depending on the whether there is an accident $(2 b)$ or not $(2 a)$.

Individuals are expected utility maximisers with state dependent utility functions: $u_{i s}\left(y_{i s}\right)(s=0$ if there is no accident, $s=1$ if there is an accident $)$. We assume that the accident imposes a loss in utility $K$ even if income levels are unaffected but that this utility loss does not depend on the income level:

$$
u_{i 0}(y)-u_{i}(y)=K>0
$$

Thus, marginal utilities of income depend only on income and not on the state.

It is useful to be able to express the loss in utility due to an accident in the following form:

$$
u_{i l}-u_{i o}=E u_{i s y}\left(y_{i s}\right)\left[y_{i l}-y_{i o}-C_{i}\right]-K=E u_{i s y}\left[\alpha_{i}-L_{i}-T_{i}-C_{i}\right]-K
$$

where $u_{i s y}=d u_{i s} / d y_{i s}$ and $E u_{i s y}$ is expected marginal utility of income. $C_{i}$ is defined by (3b) and is a measure of the utility loss due to risk aversion i.e. the concavity of the utility function. ${ }^{1}$ Figure lillustrates. Note that $C_{i}>0$ if the accident probability is small, so that $E u_{i s y}$ is close to $u_{i o y}$.

Figure 1: Effect of accident on utility.

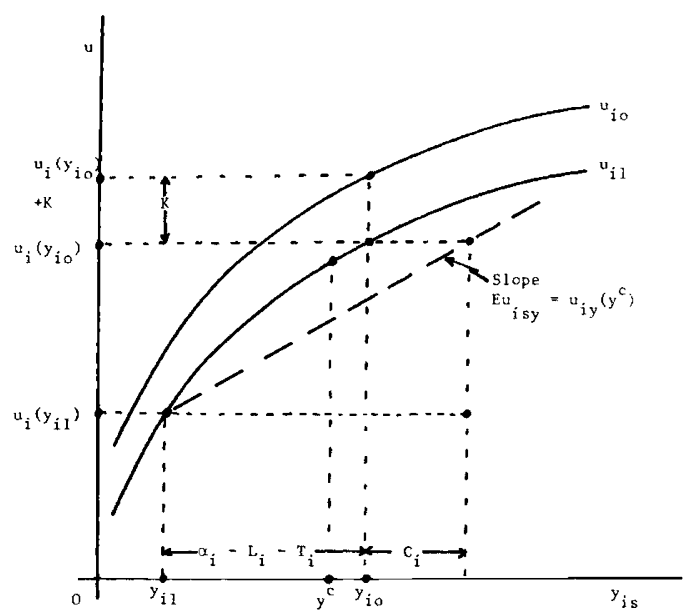

${ }^{1} C_{i}$ is closely related to the usual measures of risk aversion. Define $y^{c}$ by $u_{i y}\left(y^{c}\right)=E u_{i s y}$. Express $u_{i l}=$ $u_{i}\left(y_{i l}\right)$ and $u_{i o}=u_{i}\left(y_{i o}\right)$ as a Taylorian expansion around $y^{c}$ and then write $u_{i l}-u_{i o}=K+u_{i y}\left(y^{c}\right)\left[y_{i l}-y_{i o}\right]+$ $\left.u_{i y y}\left(y^{c}\right)\left[y_{i l}-y_{i o}\right)\left(y_{i l}+y_{i o}-2 y^{c}\right)\right](1 / 2)$. Divide by $u_{i y}\left(y^{c}\right)=E y_{i s y}$ to give $C_{i}=A_{i}\left(y^{c}\right)\left[\left(y_{i l}-y_{i o}\right)\left(y_{i l}+y_{i o}-2 y^{c}\right)\right](1 / 2)$ where $A_{i}=-u_{i y y} / u_{i y}$ is the Arrow-Platt measure of absolute risk aversion. 


\section{Expected utility is}

$$
V_{i}\left(x_{i}, \gamma_{i}, \alpha_{i}, z_{i}, T_{i}, t, x_{j}\right)=\left[1-\pi\left(x_{1}, x_{2}\right)\right] u_{i o}\left(y_{i o}\right)+\pi\left(x_{1}, x_{2}\right) u_{i l}\left(y_{i l}\right)
$$

and (4) is maximised by $i$ by choice of care $\left(x_{i}\right)$ and insurance contract $\left(\alpha_{i}, \gamma_{i}\right)$. In this private maximisation each individual assumes that neither the other individual nor the government will alter their behaviour in response to his decisions: he treats $\left(x_{j}, z_{i}, t, T_{i}\right)$ as parameters in choosing $\left(x_{i}, \alpha_{i}, \gamma_{i}\right)$.

Choice of care. Because the insurer cannot observe $x_{i}$, the terms of the insurance contract $\left(\alpha_{i}\right.$, $\gamma_{i}$ ) cannot be linked to care taken and so $x_{i}$ is chosen to satisfy ${ }^{2}$

$$
V_{i x_{i}}\left(x_{i}, \gamma_{i}, \alpha_{i}, z_{i}, T_{i}, t, x_{j}\right)=\pi_{i}\left(u_{i l}-u_{i o}\right)-p E u_{i s y}=0,
$$

where $V_{i x_{i}}=\partial V_{i} / \partial x_{i}$, and $\pi_{i}=\partial \pi / \partial x_{i}$. The care level satisfying (5) is

$$
\hat{x}_{i}=\hat{x}_{i}\left(\gamma_{i}, \alpha_{i}, z_{i}, T_{i}, t, x_{j}\right)
$$

Private insurance contract. With strictly concave $u_{i s}$ the risk averse individual will wish to buy fair insurance. The Privately efficient insurance contract will maximise $V_{\text {i }}$ subject to the moral hazard constraint (6) and to the competitive insurer's breakkeven constraint: $\gamma_{i}=\pi \alpha_{i}$. Care cannot be directly controlled by the contract, but the terms of the contract will be chosen to reflect both risk shifting and their effects on care (and thus on the insurer's costs) via (6). ${ }^{3}$ The contract will satisfy ${ }^{4}$

$$
\pi(1-\pi)\left(u_{i l y}-u_{i o y}\right)=\alpha_{i} \pi_{i} \frac{d \hat{x}_{i}}{d \alpha_{i}} E u_{i s y}
$$

As Shavell [1979] has shown the privately efficient insurance contract provides some, but less than full, cover. The left hand side of (7) is the marginal benefit from additional cover which transfers income from the no accident state (when income is high and marginal utility low) to the accident state (when income is low and marginal utility high). The right hand side is the marginal cost of additional cover which reduces care, raises $\pi$ and increases the premium. The privately efficient contract is

$$
\begin{aligned}
& \alpha_{i}^{*}=\alpha_{i}^{*}\left(z_{i}, T_{i}, t, x_{j}\right) \\
& \gamma_{i}^{*}=\pi \alpha_{i}^{*}=\gamma_{i}^{*}\left(z_{i}, T_{i}, t, x_{j}\right)
\end{aligned}
$$

${ }^{2}$ It is assumed that the direct utility $\operatorname{loss} K(3 \mathrm{a})$ is so large that some care is optimal at finite $p$.

${ }^{3}$ It will be assumed that each insured contracts with a different insurer. If an insurer contracted with both individuals, the contracts with each would reflect the direct physical externality between the insureds. In more general models, this internalisation by common insurers would mean that the relative numbers of insureds and insurers would have significant implications. It would also provide an incentive for mergers of insurers.

${ }^{4}$ Substitute $\alpha_{i} \pi$ for $\gamma_{i}$ in $V_{i}$ and differentiate with respect to $\alpha_{i}$ to get (7). The effect of cover on care takes account of the premium changes induced as $\alpha_{i}$ varies. We assume that $d \hat{x}_{i} / d \alpha_{i}<0$. 
Nash equilibrium. In choosing care and insurance cover each individual is assumed to ignore their effect on the care taken by the other individual. For a Nash equilibrium (NE) the decisions of each individual must be compatible i.e. (8) must be satified for both individuals. Under plausible assumptions a unique, stable Nash equilibrium will exist. ${ }^{5}$ The Nash equilibrium care and insurance cover of each individual will depend on the full set of government policy instruments: $\left(z_{1}, z_{2}, T_{1}, T_{2}, t\right)$. The Nash equilibrium care and insurance contract for $i$ is

$$
\begin{aligned}
& \alpha_{i}^{o}=\alpha_{i}^{o}(z, T, t,) \\
& \gamma_{i}^{o}=\pi^{o} \alpha_{i}^{o}=\gamma_{i}^{o}(z T, t,) \\
& x_{i}^{o}=x_{i}^{o}(z, T, t)
\end{aligned}
$$

and the Nash equilibrium accident probability is

$$
\pi^{o}=\pi\left(x_{1}^{o}, x_{2}^{o}\right)=\pi^{o}(z, T, t)
$$

\section{Government policy}

Welfarefunction. We assume that the government is guided by a desire to maximise a Benthamite social welfare function, which is the unweighted sum of the two individual's expected utilities

$$
W=V_{1}+V_{2}
$$

Distributional considerations thus have no influence on policy.

First best allocation. The first best allocation is achieved by an omniscent policy maker with direct control of individual incomes and care levels. This allocations is of some interest in its own right. Further, even when the policy maker has a more restrictec set of policy instruments, it is shown in section 3 (propositions 1 and 2) that it may still be possible to achieve the first best allocation.

Remembering that the constant marginal cost of care is unity, the policy maker's first best problem is to maximise (11), by choice of the $x_{i}$ and $y_{i o}, y_{i l}$, subject to the expected value resource constraint

$$
(1-\pi) \Sigma\left(y_{i}-y_{i o}\right)+\pi \Sigma\left(y_{i}-L_{i}-y_{i l}\right)-\Sigma x_{i} \geq 0
$$

The first best allocations satisfies

$$
\begin{aligned}
& u_{i o y}=u_{i l y}=\lambda \quad(i=1,2) \\
& -\pi_{i}\left\{\Sigma L_{j}+(1 / \lambda) \Sigma K_{j}\right\}=1 \quad(i=1,2)
\end{aligned}
$$

${ }^{5}$ The assumptions are (a) (8c) is continuous and $d x_{i}^{*} / d x_{j}<0 ;$ (b) $x_{i}^{*}$ is finite at $x_{j}=0 ;$ (c) $x_{i}^{*}>0$, all $x_{j}$; (d) $\Delta^{*}=1-\left(d x_{i}^{*} / d x_{j}\right)\left(d x_{j}^{*} / d x_{i}\right)>0$. 
There is complete insurance (13), since marginal utilities are equalised across states. Given the state independence of $u_{i s y}$, this is achieved by full cover insurance which equalises state incomes. In (14) $\{$.$\} is the social cost of an accident and is the sum of the monetary losses and$ the direct utility losses (recall (3a)). The left hand side of (14) is the marginal social benefit from additional care by $i$ and is set equal to its marginal cost for a first best allocation.

The Nash equilibrium is clearly not a first best allocation. In choosing $x_{i}$, individual $i$ ignores the effects of care on this insurer's expected costs and on the other individual $j$. Individual $j$ gains from additional $x_{i}$ because he faces a lower probability of a smaller utility level and be because he will pay a smaller premium to his insurer for a given amount of cover. The NE level of care is thus too low. The insurer's inability to monitor $x_{i}$ also leads to less than complete cover and, compared to the first best allocation, there is insufficient shifting of risks to the risk neutral insurer.

Feasible policies. We assume that the policy maker cannot observe care, but can levy accident taxes, tax or subsidise care and regulate private insurance. We will proceed initially by concentrating on the tax instruments $(z, T, t)$ since we demonstrate below (proposition 5$)$ that regulation of private insurance cover is not necessary if accident taxes are feasible.

Symmetry assumption. In order to derive results simply and intuitively, we assume that the two individuals have identical utility functions, initial incomes and accident losses and that the accident probability function $\pi\left(x_{1}, x_{2}\right)$ is symmetric. Faced with the same constraints the individuals will make the same decisions. Since the welfare function (11) is an unweighted sum of the individual's expected utilities, it is plausible that an optimal policy mix will have $T_{1}$ $=T_{2}$ and $z_{1}=z_{2}$, so that the identical individuals are treated equally and have the same expected utility. Surprisingly, this is not so. Our assumptions guarantee that the set of feasible $\left(V_{1}\right.$, $V_{2}$ ) is symmetric, but not that it is strictly convex. Consequently an optimal policy may have unequal accident taxes and expected utilities. (See Atkinson and Stiglitz [1976]). We will therefore impose a horizontal equity constraint on tax policy: $T_{1}=T_{2}, z_{1}=z_{2}$.

The horizontal equity constraint is reasonable in its own right and permits a significant simplification in the analysis. The government budget constraint (1) can now be replaced with

$$
\pi^{o} T_{i}+t x_{i}^{o}-z_{i}=0
$$

Substituting for $z_{i}$ in $V_{i}$, the policy problem is now to choose the accident $\operatorname{tax} T_{i}$ and care $\operatorname{tax} t$ to maximise $V_{1}+V_{2}$, given that the individuals' decisions on care and private insurance are a Nash equilibrium and satisfy (9).

Derivation of optimal taxes. The optimal taxes must satisfy

$$
\begin{aligned}
0=\frac{\partial W}{\partial T_{i}}= & \pi_{2} \frac{\partial x_{2}^{o}}{\partial T_{i}}\left(u_{11}-u_{10}\right)+\pi_{1} \frac{\partial x_{1}^{o}}{\partial T_{i}}\left(u_{21}-u_{20}\right) \\
& +\sum_{j} E u_{j s y}\left[\frac{d \pi^{o}}{d T_{i}}\left(T_{j}-\alpha_{j}^{o}\right)+t \frac{\partial x_{j}^{o}}{\partial T_{i}}\right]+\pi\left(E u_{i s y}-u_{i b y}\right)
\end{aligned}
$$




$$
\begin{aligned}
0=\frac{\partial W}{\partial t}= & \pi_{2} \frac{\partial x_{2}^{o}}{\partial t}\left(u_{11}-u_{10}\right)+\pi_{1} \frac{\partial x_{1}^{o}}{\partial T_{i}}\left(u_{21}-u_{20}\right) \\
& +\sum_{j} E u_{j s y}\left[\frac{d \pi^{o}}{d t}\left(T_{j}-\alpha_{j}^{o}\right)+t \frac{\partial x_{j}^{o}}{\partial t}\right]
\end{aligned}
$$

In deriving these expressions we have made use of the fact the care level chosen is privately optimal for each individual. In choosing $x_{i}$, the individual ignores its effect on his insurance premium $\left(\alpha_{i} \pi\right)$ (because the insurer cannot link the premium to care chosen), and on $z_{i}=\pi T_{i}+$ $t x_{i}$ (because he regards government policy as unalterable by his behaviour). Thus, the variations in care induced by government policies which are relevant in (16) and (17) are those whose marginal effects have not been allowed for by $i$ when $x_{i}$ was chosen.

In (16) the marginal effects of $T_{i}$ are of three kinds. The first two terms show the utility gain to each individual as a result of the change in the other individual's care level. The second type of effects arise because the change in the care levels of the individuals change their insurance premiums and their receipts from the government. Finally a $£ 1$ increase in $T_{i}$ has a direct effect on $V_{i}$ since, for given $\left(x_{1}, x_{2}\right)$ and $\pi, y_{i l}$ falls by $£ 1$ and income in both states increases by $\mathfrak{E} \pi$ ( since $z_{i}=\pi T_{i}+t x_{i}$ ).

The explanation of (17) is similar, except that there is no direct effect of $t$ on $V_{1}$ or $V_{2}$. For given care, the effect of $t$, via the price of care $(p=1+t)$, is exactly offset by the change in government tax revenue which is returned to the individual.

Because of the symmetry assumptions, the optimal tax policy has $T_{1}=T_{2}, u_{l s}=u_{2} s, E u_{l s y}=$ $E u_{2} s_{y}=\lambda, \alpha_{1}^{\circ}=\alpha_{2}^{o}, \pi_{1}=\pi_{2}, \partial x_{1} / \partial t=\partial x_{2}^{o} / \partial t$. Making use of $(3 \mathrm{~b})$ for $u_{i l}-u_{i o}$, the optimal tax conditions can be written.

$$
\begin{aligned}
& \frac{d \pi^{o}}{d T_{i}}\left\{\lambda\left(T_{i}-\alpha_{i}^{o}-L_{i}-C_{i}\right)-K\right\}+2 t \lambda \frac{\partial x_{i}^{o}}{\partial T_{i}}+\pi\left(\lambda-u_{i l y}\right)=0 \\
& \pi_{i}\left\{\lambda\left(T_{i}-\alpha_{i}^{o}-L_{i}-C_{i}\right)-K\right\}+t \lambda=0
\end{aligned}
$$

\section{Policy propositions}

In this section we bring out the policy implications of the model and the tax policy conditions (18), (19) in a series of propositions. We consider first the special case of risk neutral individuals.

\section{Risk neutrality}

As several earlier papers have shown, with risk neutrality a first best allocation is achievable by means of accident taxes or care subsidies, despite the government's inability to observe individual care levels.

Propositions 1 . If individuals are risk neutral, a first best allocation can be achieved by accident taxes $T_{i}=L_{j}$ or by a subsidy on care $t=\pi_{i} L_{j}<0$. 
Proof. With risk neutrality, $K=0$, marginal utility is constant, $u_{i l y}=\lambda$ and $C_{i}=0$. The individual will not buy fair insurance and $\alpha_{i}^{o}=0$. Set $t=0$. Then (18) implies $T_{i}=L_{i}=L_{j}$. Each individual will maximise $y_{i}-\pi\left(T_{i}+L_{i}\right)+z_{i}-x_{i}$ and will set $1=-\pi_{i}\left(T_{i}+L_{i}\right)=-\pi_{i}\left(L_{1}+\mathrm{L}_{2}\right)$, as required for the first best care level. Alternatively set $T_{1}=T_{2}=0$ and $t=\pi_{i} L_{j}<0$. Then $x_{i}$ is chosen to maximise $y_{i}-\pi L_{i}-(1+t) x_{i}+z_{i}$ and satisfies $-\pi_{i} L_{i}=\left(1+\pi_{i} L_{j}\right)$ and so again $1=-\pi_{i}\left(L_{1}+L_{2}\right)$.

Remarks. Informal versions of this proposition can be traced back to Vickrey [1968] or even, in the context of non-stochastic bilateral externalities, to Coase [1961, pp. 41-42]. The intuition is that since both parties can influence the accident probability, they can be motivated to take the socially correct amount of care if each individual bears all the costs of the accident, or if their care is subsidised. ${ }^{6}$

Unlike the other propositions in this paper, the assumption of identical individuals is not essential. It is readily confirmed that $T_{i}=L_{j}$ leads to first best care by both individuals even if $L_{1} \neq L_{2}$ and $\pi$ is not symmetrical. However, with non-identical individuals care subsidies will differ, with the (negative) taxes on $x_{i}$ and $x_{j}$ being $t_{i}=\pi_{i} L_{j} \neq \pi_{j} L_{i}=t_{j}$. The government must therefore be able to tax the care of each individual separately, which implies that care is observable. With non-identical individuals and individual care not being observable (though it may be possible to tax all care at a common rate) a first best ia achievable only with accident taxes.

\section{First best under risk aversion}

Returning to our identical, risk averse individuals model, we next show that under certain circumstances a first best allocation can be attained.

Proposition 2. A first best allocation of care and risk sharing can be achieved by providing full cover public insurance $(T=-L)$ and by taxing care at the rate $t=\pi_{i}\{2 L+(K / \lambda)\}<0$.

Proof. Use (19) to get $t=-\pi_{i}\left(T-\alpha^{o}-L-C-K / \lambda\right)$, where the subscripts on $T$ etc. are unnecessary because of symmetry. Substitute in (18). Remember that $d \pi^{o} / d T_{i}=\Sigma \pi_{i} \partial x_{i}^{o} / \partial T_{i}=2 \pi_{i} \partial x_{i}^{o} /$ $\partial T_{i}$ so that the first two terms in (18) cancel. Thus $u_{i l y}=\lambda=E u_{i s y}=u_{i o y}$, and there is full risk shifting. Since $u_{i s y}$ depends only on income, we must have $y_{i o}=y_{i l}$ and $\alpha^{o}=L+T$. But, with $u_{i l y}$ $=u_{i o y}, \alpha^{o}=0$. Similarly $C=0$, hence $t=-\pi_{i}\{T-L-(K / \lambda)\}$. The choice of $x_{t}$ satifies (5) and, since $u_{i l}-u_{i o}=-K$, we have $-\pi_{i} K=\lambda(1+t)$. Substituting in for $t$ gives the condition for the first best allocation of care.

Remarks. If the government has a full set of tax instruments, it can fully insure both individuals. This obviously dilutes the incentive to take care, which is now provided only because an accident impose the direct utility cost $K$ on each individual. To increase the care taken a subsidy is paid, to ensure that all of the marginal social gains from care are internalised by the individual. An analogous result is obtained in Arnott and Stiglitz [1986, pp. 21-22], where it is demonstrated that, with all goods taxable and public insurance, a first best is attainable despite the existence of asymetrical information. The difference is that in this paper there are technical extenalities (via $\pi\left(x_{1}, x_{2}\right)$ ), as well as pecuniary externalities, to be corrected by appropriately chosen commodity taxes.

\footnotetext{
${ }^{6}$ In fact, any combination of $T, t$ satisfying $t=-\pi_{i}(T-L)$ will yield a first best allocation.
} 


\section{Care subsidies with a no-fault regime}

Any legal regime which does not require the determination of care by parties to an accident as a basis for the allocation of accident costs will achieve a considerable saving in legal costs. The no-fault regime, under which no costs are shifted between parties (or between their insurers), will also avoid any administrative costs associated with collection of accident taxes or enforcement of rights to compensation. If cost shifting policy is restricted to the choice of a simple liability rule or a accident tax (such as those outlined in Section 2), the nofault regime $\left(T_{i}=0\right)$ may be attractive. If it is impossible (or very expensive) for third parties to determine accident costs (financial and psychic) and individuals are identical, then the nofault regime may be the optimal simple regime. Under such a regime individuals will take insufficient care and a care subsidy is required.

Propositions 3. Under a no-fault regime $\left(T_{i}=0\right)$ the second best optimal care subsidy is $t=\pi_{i}\left\{\alpha^{0}+\right.$ $L+C(K / \lambda)\}<0$.

Proof. Set $T_{i}=0$ in (19) and solve for $t$.

Remarks. Under a no-fault regime, private insurance provides less than full cover because of moral hazard (see (7)). The social costs of an accident therefore are due to the state dependence of the utility functions $(K \lambda)$, the monetary losses $(L)$, which are bourne by the individuals or their insurers, and the risk aversion costs $(C)$ which arise because there is incomplete cover. The care subsidy internalises these costs so that individuals choose a second best level of care. To see this, substitute $\pi_{i}\left\{\alpha^{o}+L+C+(K / \lambda)\right\}$ for $t$ and (3b) for $u_{i l}-u_{i o}$ in (5). Rearranging gives $-\pi_{i}\{L+C+(K / \lambda)\} 2=1$. Thus the choice of $x_{i}$ reflects all the marginal social gains from additional care. Without the subsidy, the choice of $x_{i}$ would satisfy $\pi_{i}\left\{\alpha^{o}-L-C-(K / \lambda)\right\}$ $=1$ and the impact of additional care on $i$ 's insurer's costs, individual $j$ 's utility and individual $j$ 's insurers costs would be ignored.

\section{Second best accident taxes}

In many contexts care may not be taxable, for example, when care is the effort, attention and anticipation involved in driving a car. If care subsidies are not feasible, the choice of cost shifting rule $\left(T_{i}\right)$ must reflects its effect on care, as well as on risk bearing. We assume, plausibly, that increases in losses bourne by an individual will reduce the probability of an accident $\left(d \pi^{0} / d T_{i}<0\right)$.

Proposition 4. If care subsidies are infeasible the second best tax satifies $-L<T<\alpha+L+C+$ $(K / \lambda)$.

Proof. Set $t=0$. With full cover public insurance $(T=-L), \alpha^{o}=0, c=0$ and $y_{i l}=y_{i o}$. The second term in (18) is zero and the first is $-\{2 \lambda L+K\} d \pi^{\circ} / d T_{i}$, so that $\partial W / \partial T_{i}>0$ at $T_{i}=0$. Conversely, if $T=\alpha+L+C+(K / \lambda)$, the first term in (18) is zero and the second is negative, since $y_{i l}<y_{i o}$ and so $\lambda-u_{i l y}=(1-\pi)\left(u_{i o y}-u_{i l y}\right)<0$.

Remarks. Since the choice of $T_{i}$ involves a trade off between better risk bearing and lower accident probabilities, it is intuitive that the second best cost shifting rule provides neither full cover insurance, nor full liability on each individual for the total costs of an accident. With full public cover for accident losses $(T=-L)$ there is optimal risk bearing, but the incentives to take care too small. An individual bears only the psychic cost $(K)$, and not the full social $\operatorname{cost} 2(K+L \lambda)$ of an accident. At $T=-L$, the marginal social value of a higher accident 
tax (reduced public insurance cover) is just $-K d \pi / d T_{i}$, which is unambiguously positive. Conversely, with $T=\alpha+L+C+(K / \lambda)$ each individual chooses care to ensure that $\lambda=2(\lambda(L+C)$ $+K)$, so that all accident costs are internalised, but there are social gains to be had from a reduction in $T$ to shift risks from the risk averse individuals. Hence, the optimal accident tax satifies $-L<T<\alpha+L+C+(K / \lambda)$.

In the next section, we use the close relationship between accident taxes and direct regulation of private insurance to show that the accident tax should in fact be positive.

\section{Accident taxes and restrictions on private insurance}

When care subsidies are feasible the state incomes are

$$
\begin{aligned}
& y_{i o}=y_{i}-x_{i}-\left(\alpha_{i}-T_{i}\right) \pi=y_{i}-x_{i}-n_{i} \pi \\
& y_{i l}=y_{i}-x_{i}-L_{i}+\left(\alpha_{i}-T_{i}\right)(1-\pi)=y_{i}-x_{i}-L_{i}+n_{i}(1-\pi)
\end{aligned}
$$

where $n_{i}$ is the net insurance cover. The privately optimal care level $x_{i}$ depends on the net cover and the government can attempt to influence the accident probability by varying $n_{i}$. If it is possible to directly control the amount of private cover $\alpha_{i}$, then $n_{i}$ can be set at any desired level by choice of the compulsory cover level, with the accident tax $T_{i}$ set at an arbitrary level (or vice versa). Alternatively, if $\alpha_{i}$ is not regulated then $n_{i}$ is controlled only via $T_{i}$. With no direct control of $\alpha_{i}$ the net cover is

$$
n_{i}^{o}=\alpha_{i}^{o}(T)-T_{i}=n_{i}^{o}(T)
$$

where $\alpha_{i}^{o}$ is the NE insurance cover.

The difficulty with indirect control of $n_{i}$ via $T$, as compared with direct control, is that not all $n_{i}$ levels can be achieved by indirect means. Changes in private cover $\alpha_{i}^{o}$ can offset the effect on $n_{i}$ of variations in the accident tax. At $T=-L, \alpha_{i}^{o}(-L)=0$ and so $n_{i}^{o}=L$. If $T=0$ (i.e. a no fault system), then, as (7) indicates, $n_{i}^{o}(0)=\alpha_{i}^{o}(0)<L$. Hence $n_{i}^{o}$ can be set in the interval $\left[L, \alpha_{i}^{o}(0)\right]$ by choice of $T$. However, it may not be possible to force $n_{i}^{o}(T)$ to any arbitrary value $n_{i}$ less than $\alpha_{i}^{o}(0)$.

It is clear that indirect control of $n_{i}^{o}$, via $T$ cannot do better, and may do worse, than direct control. Let $\left(n_{1}^{* *}, n_{2}^{* *}\right)$ be the directly controlled identical net care levels which maximise $W$ when care subsidies are not feasible. Accident taxes are effective if there exist $\left(T_{1}^{* *}, T_{2}^{* *}\right)$ such that $n_{i}^{o}\left(T^{* *}\right)=n_{i}^{* *}$.

If accident taxes are effective it is possible to characterise optimal second best accident taxes by reference to the second best net cover $\left(n_{1}^{* *}, n_{2}^{* *}\right)$. If $n_{i}$ is directly controlled the Nash equilibrium care levels satisfy (6) with $t=0$ and $z_{i}=\pi T_{i}$. NE care depends on net cover: $x_{i}(n)$ and thus so does the accident probability $\pi(n) .{ }^{7}$ The choice of net care must balance its effects on risk bearing and the accident probability.

\footnotetext{
${ }^{7}$ The NE exists and is stable under conditions analogous to those in footnote 5 for the case where $\alpha_{i}$ is not regulated.
} 
Proposition 5. If, (i) the accident probability increases with net cover $\left(\partial \pi / \partial n_{i}>0\right)$, (ii) social welfare is concave in $\left(n_{1}, n_{2}\right)$, and (iii) $\sum n_{j}^{o}(T)$ decreases with $T_{i}\left(\partial \alpha_{i}^{o} / \partial T_{i}+\partial \alpha_{j}^{o} / \partial T_{i}<1\right)$; then (a) net cover should be less than would be chosen in an unregulated no-fault regime $\left(n_{i}^{* *}<n_{i}^{o}(0)=\right.$ $\left.\alpha_{i}^{o}(0)\right) ;(b)$ the second best net cover could be negative $\left(n_{i}^{* *}<0\right)$ and (c), if insurance is not regulat$e d$, accident taxes should be positive and (d) could exceed private insurance cover $\left(T_{i}>\alpha_{i}^{o}(T)\right)$.

Proof. (a) Using the symmetry assumptions and the envelope theorem in respect to variations in $\hat{x}_{i}$ we have

$$
\frac{d W}{d n_{i}}=\frac{\partial \pi}{\partial n_{i}}\left(u_{i o}-u_{i l}\right)+\frac{\partial \pi}{\partial n_{i}} 2 \lambda n_{i}+\pi\left(u_{i l y}-\lambda\right)
$$

We show that (23) is negative at $n_{i}=\alpha_{i}^{o}(0)$ so that, by concavity $n_{i}^{* *}<\alpha_{i}^{o}(0)$. The first term in (23) is negative at $n_{i}=\alpha_{i}^{o}(0)$, since $\partial \pi / \partial n_{i}>0$. Incomes, care, accident probability and utilities at $T=0$ and $\alpha^{o}(0)$ are identical with those when $n_{i}$ is fixed at $\alpha^{o}(0)$. Hence, we can use the conditions on the privately optimal insurance cover (7) to replace $\pi\left(u_{i l y}-\lambda\right)$ in (23) with $\alpha_{i}^{o}(0) \pi_{i} \frac{d \hat{x}_{i}}{d \alpha_{i}} \lambda$. Since $d \hat{x}_{i} / d \alpha_{i}=d \hat{x}_{i} / d n_{i}$ the sum of the last two terms in (23) is

$$
-\lambda \pi_{i} \alpha_{i}^{o}(0)\left[2\left(\frac{d x_{i}^{o}}{d n_{i}}+\frac{d x_{j}^{o}}{d n_{i}}\right)+\frac{d \hat{x}_{i}}{d n_{i}}\right]
$$

Now the NE responses with direct control of net cover are $d x_{i}^{o} / d n_{i}=\Delta^{-1} d \hat{x}_{i} / d T_{i}$ and $d x_{j}^{o} / d n_{i}=$ $\left(d \hat{x}_{j} / d x_{i}\right)\left(d x_{i}^{o} / d n_{i}\right)$, where $\Delta=1-\left(d \hat{x}_{1} / d x_{2}\right)\left(d \hat{x}_{2} / d x_{1}\right)>0$ for a stable NE.

Substituting in (24) and rearranging gives

$$
-\lambda \pi_{i} \alpha_{i}^{o} \frac{d \hat{x}_{i}}{d n_{i}}\left(1+\frac{d \hat{x}_{i}}{d x_{j}}\right)^{2} \Delta^{-1}
$$

where use has been made of symmetry to write $\left(d \hat{x}_{i} / d x_{j}\right)\left(d \hat{x}_{j} / d x_{i}\right)=\left(d \hat{x}_{i} / d x_{j}\right)^{2}$. The assumption that $\partial \pi / \partial n_{i}$ is positive implies

$$
\frac{\partial \pi}{\partial n_{i}}=\pi_{i}\left(\frac{d x_{i}^{o}}{d n_{i}}+\frac{d x_{i}^{o}}{d n_{i}}\right)=\pi_{i} \frac{d \hat{x}_{i}}{d n_{i}}\left(1+\frac{d \hat{x}_{j}}{d x_{i}}\right) \Delta^{-1}>0
$$

But $\Delta=1-\left(d \hat{x}_{i} / d x_{j}\right)^{2}>0$ implies $1>-d \hat{x}_{i} / d x_{j}$ and (26) implies $d \hat{x}_{i} / d n_{i}<0$. Hence (25) is negative and so $\partial W / \partial n_{i}<0$ at $n_{i}=\alpha_{i}^{o}(0)$.

(b) With $n_{i}=0(23)$ is the sum of the negative first term and positive first term and so could be negative. (c) If accident taxes are effective, the conclusion follow from $n_{i}^{o}\left(T^{* *}\right)=\alpha_{i}^{o}\left(T^{* *}\right)-T_{i}^{* *}$ $=n_{i}^{* *}<\alpha_{i}^{o}(0)=n_{i}^{o}(0)$ and assumption (iii). Similarly for (d). Suppose accident taxes are not effective. the marginal effect of $T_{i}$ on welfare is

$$
\frac{\partial W}{\partial T_{i}}=\frac{\partial W}{\partial n_{1}} \frac{\partial n_{1}^{o}}{\partial T_{i}}+\frac{\partial W}{\partial n_{2}} \frac{\partial n_{2}^{o}}{\partial T_{i}}=\frac{\partial W}{\partial n_{i}}\left(\frac{\partial n_{1}^{o}}{\partial T_{i}}+\frac{\partial n_{2}^{o}}{\partial T_{i}}\right)
$$


At $\left(n_{1}, n_{2}\right)=\left(\alpha_{1}^{o}(0), \alpha_{2}^{o}(0)\right),(27)$ is positive since $\partial W / \partial n_{i}<0$ and by assumption (iii) increases in $T_{i}$ reduce the combined net cover $\Sigma n_{j}^{o}$.

Remarks. Private insurance contracts with asymmetrical information achieve an allocation of risk bearing and care takem, which is efficient as far as the parties to the contracts are concerned. If there are no external effects on third parties, the only grounds for government intervention is to further mitigate moral hazard. Since the insurer and insured have already allowed for the effect of insurance on care, there can be no efficiency gain from government regulation of the insurance contract. Thus, as Shavell [1982, pp. 127-130] has shown, in the case of unilateral accidents, where the insurer is strictly liable to compensate the victim for all losses, there are no grounds for restrictions on private insurance, even in the presence of moral hazard. Only if the government has information or instruments (such as commodity taxes or subsidies) which are not available to insurer, can it improve on the allocation achieved by privately efficient insurance contracts.

In the case of bilateral accidents the insurance contracts fail to reflect the effect of care on third parties (and their insurers). There are grounds for direct regulation of insurance, or accident taxes, to increase care levels. But accident taxes and regulation of insurance are almost perfect policy substitutes. An increase in the accident tax transfers income from the accident to the no-accident state, and so does a reduction in private insurance. Both will increase care.

Although regulation of insurance cover and accident taxes may achieve identical allocations when used separately, achievement of the second best allocation may require the use of both instruments. If individuals adjust their insurance cover to offset the effect of accident taxes, it may not be possible to achieve the second best allocation by relying solely on accident taxes. Conversely, there may be constraints on the regulation of insurance contracts. For example, if the second best net cover is negative, the regulated private insurance contract takes the peculiar form of a negative premium in exchange for the insured paying the insurer if the accident occurs. Rather than force individuals into such bonding contracts, it may be easier to simply bar private insurance and impose an accident tax.

Calculation of the second best accident tax or net cover requires considerable information on technology and preferences. Unlike the risk neutral case, knowledge of the accident loss $\left(L_{i}\right)$ will not be sufficient. We have, however, been able to show that the no-fault system $(T=0)$ provides insufficient incentives for care compared with the second best level. A nofault rule needs to be supplemented either with an accident tax or with limitations on private insurance cover.

\section{The participation problem}

One possible problem with accident taxes is that, although they encourage care, they may discourage participation in risky activities. They could lead individuals to stop indulging in activities which are socially beneficial. Suppose we chose the identical cardinal representations of individual preferences so that the utility from non-participation in the risky activity is zero. Then individuals participate if, and only, if $V_{i} \geq 0$. Suppose that accident taxes are levied and the revenue from them is not returned to the individuals (i.e. $\left.z_{i}=0\right){ }^{8}$ The social benefit

${ }^{8}$ Alternatively, if the accident tax revenue could be returned by way of a subsidy which is not contingent on participation in the activity, social benefits from participation could exceed private benefits. 
from the risky activity is $\Sigma V_{i}+G\left(\pi \Sigma T_{i}\right)$, where $G($.$) is the social value of government tax reve-$ nue. It is possible that $\Sigma V_{i}+G>0$, but $V_{i}<0$, so that individuals do not voluntarily participate in the risky activity, even though it is socially beneficial. The accident tax scheme examined in this paper does not suffer from participation disincentives because the proceeds of accident taxes are returned to the individuals (by $z_{i}$ ) only if they participate.

Proposition 6. With identical individuals, optimal horizontally equitable, actuarily fair accident taxes and care subsidies will not discourage socially beneficial participation in risky activities.

Proof. With $z_{i}=\pi T_{i}+t x_{i}$ being returned to participants, the social welfare function is $\sum V_{i}\left(T_{1}\right.$, $\left.T_{2}, t\right)$. The optimal taxes $\left(T_{1}^{*}, T_{2}^{*}, t^{*}\right)$ satisfy $\Sigma V_{i}\left(T_{1}^{*}, T_{2}^{*}, t\right) \geq \sum V_{i}(0,0,0)$. Since individuals are identical and participate in the absence of government intervention, $V_{i}\left(T_{1}^{*}, T_{2}^{*}, t^{*}\right) \geq V_{i}(0,0,0)$ $\geq 0,(i=1,2)$. Thus $\sum V_{i}\left(T_{1}^{*}, T_{2}^{*}, t^{*}\right) \geq 0$ and both individuals participate on the activity if it is socially beneficial.

Remarks. With activities such as car driving it is not difficult to conceive of ways of returning accident tax revenue only to those who participate. For example, in the United Kingdom, accident tax revenue could be used to finance reductiuuons in the road fund licence (a tax levied on ownership of cars). The identical individuals assumptiuon is less plausible. There may be some individuals whose care is highly productive in reducing accident probabilities, but who do not suffer large accident losses. An optimal set of accident taxes, if actuarily fair $\left(T_{i} \pi=z_{i}\right)$, could lead to such individuals suffering high taxes and being better off not participating. Such individuals would have to be subsidised (face $T_{i}<z_{i} / \pi$ ) by other participants (who would face $T_{j}>z_{j} / \pi$ ).

\section{The reporting problem}

In order to levy accident taxes the government must know that there has been an accident. Second best accident taxes are positive and may make it worthwhile for both parties to conceal the accident to avoid the accident taxes. Suppose individuals do not take out private insurance (perhaps because they are risk neutral, or there is a high loading for a administration costs). If the accident is reported and taxes levied, the two individuals lose $\Sigma T_{i}+\Sigma L_{i}$. If they agree not to claim (and thus avoid the accident taxes) their total loss is just $\Sigma L_{i}$. Hence, there is an incentive not to report (see Green [1976, p. 554]).

If individuals are insured, the obligation to report can be placed on their insurers. If individuals claim from their insurers their total loss is $\Sigma T_{i}+\Sigma L_{i}-\Sigma \alpha_{i}^{o}$. If they agree not to claim (and thus avoid accident taxes) their total loss is $\Sigma L_{i}$. If $\Sigma T_{i}<\Sigma \alpha_{i}^{o}$ at least one individual is better off claiming and taxes are levied on both. No side payment can be made which will leave both better off not claiming. Thus, as Hindley and Bishop [1983, pp. 67] suggest, the reporting problem may not arise if there is private insurance. However, it is possible (proposition 5) that accident taxes exceed private $\operatorname{cover}\left(T_{i}>\alpha_{i}^{o}\right)$. With $\Sigma T_{i}>\Sigma \alpha_{i}^{o}$ there will always exist a side payment which will make both parties better off not reporting.

It is possible to devise a self-policing system of fines for non-reporting which ensures that accidents are always reported.

Proposition 7. Consider a fine and reward system under which, if one individual reports an accident, and the other does not, he is paid a reward $0<r>\Sigma T_{i}-\Sigma \alpha_{i}$, and the non-reporter is fined an amount $f>0$. If both report, neither is fined or rewarded. This system will lead to all accidents being reported. 
Proof. After an accident occurs, the two individuals play a game in which each has two strategies: report (R) or not report (NR) and strike a bargain involving a side payment $B$ (positive or negative) from individual 1 to individual 2 . Figure 2 illustrates, the entries in each of the four quadrants showing the reduction in income for each individual as a result of the accident. The fine-reward system ensures that $R$ is the dominant strategy for both payers. For this to be so it must be true that $\alpha_{1}-L_{1}-T_{1}+r>-L_{1}-B, \alpha_{1}-L_{1}-T_{1}>\alpha_{1}-L_{1}-T_{1}-f, \alpha_{2}-L_{2}-T_{2}+r>B-L_{2}$, $\alpha_{2}-L_{2}-T_{2}>\alpha_{2}-L_{2}-T_{2}-f$. The second and fourth of these inequalities holds for any $f>0$. The first and third require that $r>T_{1}-\alpha_{1}-B$ and $r>T_{2}-\alpha_{2}+B$. But $T_{1}-\alpha_{1}-B>0$ and $T_{2}-\alpha_{2}+B>0$, otherwise one individual is made worse off by the bargain not to report. Hence $r>\Sigma T_{i}-\Sigma \alpha_{i}$, being greater than the sum of two positive numbers $\left(T_{1}-\alpha_{1}-B, T_{2}-\alpha_{2}+B\right)$, must be greater than both of them. If $\Sigma T_{i}<\Sigma \alpha_{i}$, no side payment will be made $(B=0)$ and at least one party has $\alpha_{i}-T_{i}-L_{i}+r>-L_{i}$, making $\mathrm{R}$ his dominant strategy.

\section{Individual 2}

\begin{tabular}{|c|c|c|}
\hline & Not Report & Report \\
\hline Not Report & $\begin{array}{l}-L_{1}-B \\
\quad B-L_{2}\end{array}$ & $\begin{array}{l}a_{1}^{0}-T_{1}-L_{1}-f \\
a_{2}^{0}-T_{2}-L_{2}+I\end{array}$ \\
\hline Individual 1 & & \\
\hline Report & $\begin{array}{l}a_{1}^{0}-T_{1}-L_{1}+\mathrm{T} \\
a_{1}^{0}-T_{2}-L_{2}-\mathrm{f}\end{array}$ & $\begin{array}{l}\alpha_{1}-T_{1}-L_{1} \\
\alpha_{2}^{0}-T_{2}-L_{2}\end{array}$ \\
\hline
\end{tabular}

Figure 2: The motorists' dilemma.

Remarks. With $f=r=0$ and $\Sigma T_{i}>\Sigma \alpha_{i},(\mathrm{NR}, \mathrm{NR})$ is a strict Nash equilibrium strategy pair in the post accident reporting game. ${ }^{9}$ Given NR individual $i, \mathrm{NR}$ is strictly better than $\mathrm{R}$ for individual $j$. The fine-reward system turns the game into a prisoners' dilemma. With $f>0, r>\Sigma T_{i}$ $-\Sigma \alpha_{i}, \mathbf{R}$ becomes the dominant strategy and $(\mathbf{R}, \mathbf{R})$ the unique strict Nash equilibrium strategy pair.

${ }^{9}$ All other strategy combinations are weak Nash equilibria: given the choice by $i, j$ does no better by choosing some other strategy. 
Repeated prisoners' dilemma games need not result in $(R, R)$ choices at each round of the game. The ability to sustain (NR, NR) as a strict Nash equilibrium outcome at each round requires that the players do not discount the future too heavily and that the probability of playing the game (i.e. having an accident) is large. (See Axelrod [1984]). With small accident probabilities, it seems unlikely that (NR, NR) would emerge as the strategy pair. ${ }^{10}$

Notice that, with $(R, R)$ being the unique Nash equilibrium for the reporting game both parties report, and so neither is rewarded of fined. The system is thus self-policing and costless.

\section{Conclusions}

We have shown that there are circumstances in which government policy may lead to a more efficient sharing of risks and choice of care. If private insurers cannot monitor care by insureds, and accident probabilities are influenced by the care of both parties to an accident, it is not surprising that the market equilibrium is characterised by insufficient risk shifting and too little care. However, our results are rather stronger than this, because we do not assume that policy makers are better informed than private insurers. Even when the policy maker is unable to monitor individual care levels, it is possible to improve the allocation of resources and risks by government tax policies. The government's ability to increase efficiency stems from superior policy instruments which are not available to private individuals, not from superior information.

If the government can subsidise care (which does not require that each individuals behaviour can be observed), then it is possible to achieve a first best allocation. The care subsidy increases the care taken and full public insurance cover shifts all risks away from the risk averse individuals. In the more usual circumstances that care is not taxable, the imposition of accident taxes, paid by both parties to an accident, is required. A system of no fault liability, in which each individual bears only his accident costs, does not provide sufficient incentive for care. It is necessary to increase the loss each bears in the event of an accident, in order to make care choices reflect the benefits to the other party from a reduction in the probability of an accident. With risk neutral individuals the accident tax on one individual should be equal to the loss suffered by the other. If there is risk aversion the accident tax should be rather less than this, but may still be larger than the private insurance cover taken out. The incentives not to report accidents and so avoid the tax can be avoided by a simple self-policing system of fines and rewards.

Although private insurance blunts the incentives to take care there is no point in restricting private insurance cover if accident taxes are effective. An increase in an accident tax provides the same incentive to avoid an accident as a reduction in the amount of private insurance cover.

10 Suppose individuals are identical, risk neutral and do not discount future income. A tit for tat (TFT) strategy of initially choosing NR and then choosing whatever the other player chose last time, is better than the strategy of choosing $\mathrm{R}$ at any time when the other player also plays TFT, if and only if, $\pi>$ $(\alpha-T+r) / r$. Since $r>2(T-\alpha), \pi$ must be at least $1 / 2$ for both to choose TFT and thus for (NR, NR) to be the outcome every time there is an accident. This critical minimum probability tends to 1 as $r$ is increased. Hence, by suitable choice of $r$, TFT can be made worse than the alternative strategy of choosing $\mathbf{R}$ at any time. (See Axelrod [1984, Ch. 1]). 
Accident taxes do not lead to full efficiency, because the policy maker must balance their beneficial effects on care and accident probabilities against their detremental effects on risk bearing. Thus, there is scope for further improvement to be made. The most obvious means is by attempts, albeit imperfect, to use the state's greater coercive powers to monitor and regulate care levels.

\section{REFERENCES}

ARNOTT, R. and STIGLITZ, J.E. [1986]: "Moral hazard and optimal commodity taxation", Jourmal of Public Economics, 29 (1986), 1-4.

ATKINSON, A.B. and STIGLITZ, J.E. [1976]: "The design of tax structure: direct versus indirect taxation", Journal of Public Economics, 6 (1976), 55-75.

AXELROD, R. [1984]: The Evolution of Cooperation, Basic Books, New York, 1984.

BOYER, M. and DIONNE, G. [1985]: "Sécurité routière et responsabilité pour négligence et tarification", Canadian Journal of Economics, 18 (November 1985), 814-830.

BROWN, J.P. [1973]: “Towards an economic theory of liability”, Joumal of legal Studies, 2 (June 1973), 323-350.

COASE, R.H. [1960]: "The problem of social cost", Journal of law and Economics, 3 (October 1960), 1-44.

DIAMOND, P.A. [1974]: "Single activity accidents", Journal of Legal Studies, 3 (January 1974), 107-164.

DIAMOND, P.A. and MIRRLEES, J.A. [1975]: "On the assignment of liability: the uniform case", Bell Journal of Economics, 6 (Autumn 1975), 487-516.

GRAVELLE, H.S.E. [1986]: "Insurance and corrective taxes in the health care market", Journal of Economics (Zeitschrift für Nationalökonomie), Suppl. 5 (1986), 99-120.

GREEN, J. [1976]: “On the optimal structure of liability laws", Bell Journal of Economics, 7 (Autumn 1976), 553-574.

HANSSON, I. and SKOGH, G. [1987]: "Moral hazard and safety regulation", Geneva Papers in Risk and Insurance, (1987), 132-144.

HINDLEY, B. and BISHOP, B. „1983]: “Accident liability rules and externality”, International Review of Law and Economics, 3 (June 1983), 59-68.

KNOEBER, C.R. [1978]: "Penalties and compensation for auto accidents", Journal of Legal Studies, 6 (June 1978), 263-278.

LANDES, E. [1982]: "Insurance, liability and accidents: a theoretical and empirical investigation of the effect of no-fault accidents", Journal of Law and Economics, 25 (April 1982), 49-66.

SHAVELL, S. [1979a]: "Risk-sharing and incentives in the principal-agent relationship", Bell Journal of Economics and Management Sciences, 10 (Spring 1979), 55-73.

SHAVELL, S. [1979b] : “On moral hazard and insurance”, Quarterly Journal of Economics, 93 (November 1979), $541-562$.

SHAVELL, S. [1980]: "Strict liability versus negligence", Journal of Legal Studies, 9(January 1980), 1-26.

SHAVELL, S.: "On liability and insurance", Bell Journal of Economics, 23 (Spring 1982), 120-132.

SKOGH, G. [1982]: "Public insurance and accident prevention", International Review of Law and Economics, 2 (June 1982), 67-80.

TULLOCK, G. [1981]: "Negligence again”, International Review of Law and Economics, 1 (June 1981), 51- 62.

VICKREY, W. [1968]: “Automobile accidents, tort law, externalities and insurance”, Law and Contemporary Problems, 33 (1968), 464-487. 